\title{
El tercer peronismo y la última dictadura desde las revistas políticas argentinas.
}

Reseña del libro de Marcelo Borrelli (Director) Las revistas políticas argentinas. Desde el peronismo a la dictadura (1973-1983). Buenos Aires: Prometeo, 2021, 258 págs.

\author{
Sebastián Ezequiel Ruiz \\ sebastianezruiz@gmail.com \\ Escuela Interdisciplinaria de Altos Estudios Sociales / \\ Universidad Nacional de General San Martín, \\ Argentina
}

Cita sugerida: Ruiz, S. E. (2022). El tercer peronismo y la última dictadura desde las revistas políticas argentinas [Revisión del libro Las revistas políticas argentinas. Desde el peronismo a la dictadura (1973-1983) por M. Borrelli]. Sociohistórica, 49, e168. https://doi.org/10.24215/18521606e168

Marcelo Borrelli es docente e investigador en comunicación y ciencias sociales, con una vasta trayectoria en el estudio de las revistas políticas argentinas. El presente libro es una compilación de artículos escritos en forma conjunta -excepto dos, de autoría exclusiva del director- con otros investigadores e investigadoras que formaron parte de proyectos de investigación coordinados por Borrelli. La obra se enmarca dentro de los estudios sobre la prensa política argentina durante la década de 1970 y se dedica a analizar la postura de algunas revistas comerciales de orientación política entre 1973 y 1983. La hipótesis central del libro sostiene que las revistas políticas tenían la capacidad de pasar bajo el radar de la censura oficial -debido a su tirada modesta-, y por ello tuvieron mayor margen para "influir" sobre la política y para tratar temas omitidos en publicaciones de gran tirada, en un contexto signado por la conflictividad social y política. 
El libro posee el formato característico en las compilaciones de artículos, con una muy breve presentación, sin introducción ni conclusión. Estructuralmente, se divide en dos partes que funcionan como arcos temporales, cuya línea divisoria es el golpe de Estado de 1976. La primera parte, formada por los cinco artículos iniciales, se centra en el tercer peronismo, desde la asunción de Héctor Cámpora hasta el golpe de Estado (1973-1976), mientras que la segunda parte, compuesta por seis artículos, se dedica a la última dictadura militar (1976-1983). Los artículos poseen una breve introducción al contexto histórico-político del país, una caracterización de cada revista y el desarrollo de los temas propuestos, y cierran con una conclusión que sintetiza los argumentos centrales. La lectura ordenada propone un relato cronológico del proceso histórico y, en simultáneo, el análisis de estudios de caso que permiten dar cuenta de los posicionamientos políticos de las revistas estudiadas.

A la vez, los artículos que componen el libro pueden dividirse en dos subcategorías. Por un lado, gran parte de ellos se ocupan de estudiar una revista concreta en un período acotado dentro del arco temporal correspondiente; por otro, una minoría se dedica a comparar las posturas de varias revistas sobre temas concretos, como la muerte de Perón, el Mundial de fútbol de 1978 o la guerra de Malvinas. Los autores dan cuenta de las coordenadas ideológicas de cada publicación, su posicionamiento ante el contexto político, su materialidad (calidad de edición, publicidades, distribución), sus colaboradores y las estrategias enunciativas que utilizaban para delimitar sus lectores modelo.

En la primera parte del libro, los autores tratan una serie de temas ubicados cronológicamente entre 1973 y 1976. En el primer artículo, Borrelli y Micaela Iturralde se ocupan de la revista Extra desde la asunción de Héctor Cámpora hasta la muerte de Perón (1973-1974). Utilizando herramientas del análisis del discurso, los autores presentan el perfil de la revista, delimitado por el pragmatismo de su director Bernardo Neustadt, su posición "centrista" y su estilo periodístico directo y confrontativo. Si bien en sus páginas se defendía la institucionalidad y se condenaba la violencia, la balanza se inclinaba en contra de los sectores combativos opuestos al gobierno, lo que llevó a la revista a apoyar, dentro de los límites legales, el proceso de "depuración ideológica" emprendido por el gobierno peronista.

En el segundo artículo, Borrelli se centra en la postura de Cuestionario ante la tercera presidencia de Perón (1973-1974). El autor da cuenta del perfil intelectual-académico de la revista, que ofrecía un análisis "razonado" y "sin fanatismos", y su orientación cercana a la izquierda nacional y el desarrollismo frondicista. La revista adoptó una postura de "honestidad" y transparencia, e incluyó a sus lectores como participantes activos en el debate de ideas, impronta distintiva en un contexto signado por el faccionalismo. Cuestionario apoyó críticamente la asunción de Perón y se cuestionó sobre la incertidumbre ante el eventual fallecimiento del caudillo. Tras la muerte de Perón, la revista indicó que la presidenta y esposa del líder no debía intentar "controlar el movimiento" y que debía implementar la tan postergada "actualización" de la doctrina.

El tercer artículo, escrito por Borrelli y Patricia Orbe, es el primero de los tres destinados a una mirada comparativa transversal sobre procesos históricos. Los autores analizan el fallecimiento de Perón y sus consecuencias a partir de Carta Politica, Cuestionario, Extra, Panorama y Redacción. Borrelli y Orbe caracterizan sintéticamente las publicaciones, sus perfiles ideológicos y sus lectores modelo. Luego, se centran en los comentarios de las publicaciones sobre el retorno de Perón y en las declaraciones posteriores a su muerte, que en general coincidieron sobre la necesidad del apoyo a su sucesora. En este capítulo se introduce el recurso gráfico pues se muestran algunas de las tapas más icónicas como apoyatura para la explicación de las ideas presentes en las revistas.

El cuarto artículo, escrito por Borrelli y Eduardo Raíces, se centra en las preocupaciones de la revista liberal-conservadora Carta Política en torno del orden social, del liderazgo político de Perón y de las medidas económicas implementadas por el gobierno durante 1974. Mientras la publicación aprobaba la estabilidad política que Perón ofrecía, la preocupación del medio por la rentabilidad empresarial se vislumbró en sus frecuentes críticas al Pacto Social, al intervencionismo estatal y a la redistribución de la riqueza. Tras la muerte de Perón, la publicación sostuvo la necesidad de sostener la institucionalidad, por medio del apoyo a Isabel 
y de la recuperación del monopolio de la violencia por parte del Estado. La revista recibió con beneplácito la renuncia del ministro de Economía José Ber Gelbard, de orígenes en la izquierda comunista, y su reemplazo por el economista ortodoxo Alfredo Gómez Morales.

En el quinto artículo, Borrelli y Jorge Saborido analizan el período transcurrido entre el "Rodrigazo" y el golpe de Estado (junio de 1975-marzo de 1976) a partir de los editoriales de Redacción. Destinada a los sectores medios profesionales, Redacción se amparó en una pretendida "objetividad" para presentar sentencias políticas como hechos observables, al mismo tiempo que omitía u ocultaba lo que no cuadraba en la línea política de la revista. En sus páginas fueron frecuentes la crítica al peronismo, en particular a Isabel Perón por su "impericia" e "inmoralidad", y la idea del "vacío de poder", ampliamente difundida en la prensa de la época. Los autores dan cuenta del discurso de justificación e inevitabilidad del golpe presentado por Redacción, sostenido por la construcción de una imagen distorsionada de unas Fuerzas Armadas sin vocación política y con la "imposibilidad genética" de la Argentina para lograr la estabilidad institucional.

La segunda parte del libro se inicia con el artículo de Borrelli y Alejandro Cánepa sobre Panorama durante los primeros años de la dictadura (1976-1977). La revista proponía un enfoque sofisticado destinado a un público culto, y presentaba el golpe como un "desenlace inevitable", culpando totalmente al peronismo y lavando la responsabilidad de las FF. AA. En sus páginas, el presidente de facto Videla era caracterizado como "moderado" y "abierto al diálogo". Inicialmente, Panorama intentó oficiar como canal de diálogo entre el gobierno y los partidos políticos, aunque luego criticó la demora del "descongelamiento" de la actividad política. En lo económico, la revista proponía una mirada industrialista de tipo desarrollista y cuestionó la política económica de Martínez de Hoz. Aunque la represión no era uno de sus temas centrales, Panorama reivindicó la postura oficial de la "lucha antisubversiva" y abordó las denuncias internacionales por violaciones a los derechos humanos como parte de una maniobra extranjera que buscaba desprestigiar al gobierno militar.

En el séptimo artículo, Borrelli y María Paula Gago analizan los primeros años de la dictadura desde Somos, revista destinada a los sectores de la clase media y empresarial simpatizantes de la dictadura. Los autores sostienen que la revista buscaba influir sobre las decisiones políticas del gobierno de facto y que apostó a modelar la opinión pública con ese fin. La revista adjudicaba la responsabilidad del "caos" a los partidos políticos mayoritarios, mientras que los militares eran presentados como los encargados de "refundar" el país. En lo económico, Somos apoyó críticamente al ministro Martínez de Hoz, a quien acusaron de "gradualista". En sus páginas resultó frecuente la patologización de la "subversión", y su explicación, un problema de delincuencia y de "infiltración" de ideas extranjeras. En sus balances anuales, Somos reivindicó al gobierno militar, aunque llamó la atención, al igual que Panorama, sobre la falta de un proyecto político de largo plazo.

En el octavo artículo, Borrelli y Laura Oszust se centran en los posicionamientos de Extra, Redacción y Somos ante el Mundial de fútbol de 1978. Los autores sostienen que mientras el gobierno militar utilizó el torneo para mejorar la imagen internacional del país, los medios de comunicación oficiaron como reproductores y legitimadores de ese discurso. En el caso de Extra, Borelli y Oszust analizan las declaraciones de la revista sobre el beneficio político que el Mundial trajo al gobierno militar, ya que mejoró su imagen pública ante las "calumnias" de las denuncias internacionales por las violaciones a los derechos humanos, calificadas por la revista como "propaganda antiargentina". Mientras que Somos presentó un tratamiento similar del Mundial, en Redacción convivieron apoyos con miradas críticas que lo consideraban una distracción de los problemas reales. Los autores concluyen que las tres publicaciones buscaron, por un lado, influir sobre sus lectores respecto de la valoración positiva del Mundial, defendiendo al gobierno de las acusaciones internacionales y celebrando el accionar "ordenado" de la población; y, por otro, influir sobre el gobierno militar para lograr una apertura gradual al diálogo democrático.

En el noveno apartado, Borrelli analiza la presidencia de Jorge Videla (1976-1981) a través de Redacción. El autor expone el surgimiento de la publicación, ya tratado en capítulos anteriores, y da cuenta de los balances anuales de la revista. Sin cuestionar la legitimidad del gobierno militar, Redacción demandó el 
"descongelamiento" de los partidos políticos, para llevar a cabo un proyecto de articulación cívico-militar. Hacia 1978, la falta de respuesta llevó a la revista a indicar que la actitud presidencial propiciaba un "vacío político" que arrastraría al gobierno. Tras el anuncio del "diálogo político" y la asunción a la presidencia de Roberto Viola (1981), Redacción comenzó a distanciarse del gobierno militar, junto con otros sectores civiles que vieron decepcionadas sus expectativas.

El décimo artículo, escrito por Borrelli y Raíces, aborda la revista peronista Línea, dirigida por el revisionista José María Rosa entre 1980 y 1982. Línea fue la única de las publicaciones analizadas que criticó abiertamente a la dictadura. Cercana al peronismo "verticalista" y al discurso de "reconciliación" característico de la Iglesia católica, Linea cuestionó a la dirigencia militar y condenó la marginación política de las mayorías. El artículo estudia el lugar de enunciación de Linea mediante el análisis del discurso de sus tapas y contratapas; el censo nacional y la celebración de Navidad fueron el telón de fondo para criticar la represión, las detenciones por motivos políticos y las desapariciones. Hacia 1981, la revista demandó desde sus tapas la finalización de la "dictadura", categoría poco frecuente en la prensa para ese momento, pese al notable desprestigio de la dictadura ante la opinión pública. Respecto de la política económica, Línea dirigió sus críticas y sátiras hacia Martínez de Hoz y alertó tempranamente acerca de los perniciosos efectos de las políticas liberales sobre la economía del país.

En el último artículo, Borrelli y María Paula Gago analizan las revistas Somos, Extra y Redacción ante la Guerra de Malvinas (1982), con el fin de diferenciar los posicionamientos de medios que, como se ha visto en los artículos anteriores, eran similares en orientación política y en su apoyo al gobierno militar. Tras explicar las erradas predicciones de la dictadura, Borrelli y Gago indican que Extra presentó la guerra como un acto heroico vinculado con el reclamo histórico de soberanía y justificó pragmáticamente el acercamiento al bando soviético y a los Países No Alineados. En el caso de Redacción, los autores indican que, ante la guerra, la revista abandonó su postura analítica para realizar análisis sesgados por el fervor patriótico, y dan cuenta de los recursos argumentativos utilizados para convocar a sus lectores (hipérbole, apelación al patriotismo y al "nosotros" inclusivo). A diferencia de Extra y Redacción, Somos mostró su desconfianza respecto del fervor patriótico y del riesgo que los desajustes económicos y las manifestaciones “populistas" podían causar al gobierno militar. Las tres publicaciones coincidieron, con matices, en la necesidad de una rápida transición a la democracia tras la derrota.

Debe advertirse que una dificultad que presenta el libro es la repetición textual de pasajes -y en algunos casos, páginas completas- entre capítulos. Mientras que los artículos que estudian un caso comienzan con un breve contexto histórico y luego desarrollan las hipótesis, los que comparan varios casos suelen repetir el contexto y la caracterización general de cada revista. Siendo que los artículos están cuidadosamente enhebrados para establecer una línea cronológica y el director del volumen es autor o coautor de todos los artículos, la repetición resulta prescindible. Si bien esto no condiciona la lectura del libro, la articulación entre capítulos podría ser más fluida realizando una contextualización previa a cada sección, en lugar de repetirla en cada artículo.

En conclusión, el libro es una compilación de artículos que da cuenta del posicionamiento de revistas políticas de diferentes orientaciones ante los procesos históricos del tercer peronismo y de la última dictadura militar. El uso de herramientas como el análisis del discurso político y la interpretación de la imagen propia del humor gráfico, ofrecen al lector un abanico variado de metodologías para el estudio de la prensa. Si bien por momentos la lectura continuada se dificulta por la repetición de los contextos históricos en artículos que tratan un mismo período, el libro cumple su objetivo de sintetizar el contenido principal de las publicaciones respecto de los temas propuestos, sus líneas editoriales, sus lectores deseados y sus lugares de enunciación. En simultáneo, los autores ensamblan por partes el contexto histórico de cada revista, lo que permite conservar el diálogo de escalas entre la publicación y su círculo y la coyuntura. 